\title{
The Constructive, Destructive, and Reconstructive Power of Social Norms
}

P.WesleySchultz, JessicaM.Nolan, RobertB.Cialdini, ${ }^{2}$ NoahJ.Goldstein, ${ }^{3}$ andVladasGriskevicius ${ }^{3}$

${ }^{1}$ California State University, San Marcos; ${ }^{2}$ University of Arkansas; and ${ }^{3}$ Arizona State University

ABSTRACT—Despite a long tradition of effectiveness in laboratory tests, normative messages have had mixed success in changing behavior in field contexts, with some studies showing boomerang e ffects. To test a theoretical account of this inconsistency, we conducted a field experiment in which normative messages were used to promote household energy conservation. As predicted, a descriptive normative message detailing average neighborhood usage produced either desirable energy savings or the undesirable boomerang effect, depending on whether households were already consuming at a low or high rate. Also as predicted, adding an injunctive message (conveying social approval or disapproval) eliminated the boomerang effect. The results offer an explanation for the mixed success of persuasive appeals based on social norms and suggest how such appeals should be properly crafted.

Address correspondence to Wesley Schultz, Department of Psychology, California State University, San Marcos, CA 92078, e-mail: wschultz@csusm.edu. 
After several decades of controversy over the role of norms in predicting behavior, the research has clearly established that social norms not only spur but also guide action in direct and meaningful ways (Aarts \& Dijksterhuis, 2003; Cialdini, Kallgren, \& Reno, 1991; Darley \& Latané, 1970; Goldstein, Cialdini, \& Griskevicius, 2006; Kerr, 1995; Terry \& Hogg, 2001). Given this asserted power of social norms, during the past decade there has been a surge of programs that have delivered normative information as a primary tool for changing socially significant behaviors, such as alcohol consumption, drug use, disordered eating, gambling, littering, and recycling (e.g., Donaldson, Graham, \& Hansen, 1994; Larimer \& Neighbors, 2003; Neighbors, Larimer, \& Lewis, 2004; Schultz, 1999; Schultz,

Tabanico, \& Rendón, in press). Such social-norms marketing campaigns have emerged as an alternative to more traditional approaches (e.g., information campaigns, moral exhortation, fear- inducing messages) designed to reduce undesirable conduct (Donaldson, Graham, Piccinin, \& Hansen, 1995).

The rationale for the social-norms marketing approach is based on two consistent findings: (a) The majority of individuals overestimate the prevalence of many undesirable behaviors, such as alcohol use among peers (e.g., Borsari \& Carey, 2003; Prentice \& Miller, 1993), and (b) individuals use their perceptions of peer norms as a standard against which to compare their own behaviors (e.g., Baer, Stacy, \& Larimer, 1991; Clapp \& McDonell, 2000; Perkins \& Berkowitz, 1986). Social-norms marketing campaigns seek to reduce the occurrence of deleterious behaviors by correcting targets' misperceptions regarding the behaviors' prevalence. The perception of prevalence is commonly referred to as the descriptive norm governing a behavior (Cialdini et al., 1991).

Social-norms marketing campaigns have been deemed so full of promise that nearly half of 746 U.S. colleges and universities surveyed by the Harvard School of Public Health in 2002 had adopted them in some form to combat collegiate binge drinking (Wechsler et al., 2003). However, despite the widespread adoption of social-norms marketing campaigns, evidence for the success of such programs has been surprisingly mixed. Although many studies appear to confirm the effectiveness of the social marketing approach (e.g., Agostinelli, Brown, \& Miller, 1995; Haines \& Spear, 1996; Neighbors et al., 2004), other studies have failed to produce substantial changes in behavior (e.g., Clapp, Lange, Russell, Shillington, \& Voas, 2003; Granfield, 2005; Peeler, Far, Miller, \& Brigham, 2000; Russell, Clapp, \& DeJong, 2005; Werch et al., 2000). In fact, some studies indicate that social-norms marketing campaigns have actually increased the undesirable behaviors and misperceptions they set out to decrease (e.g., Perkins, Haines, \& Rice, 2005; Wechsler et al., 2003; Werch et al., 2000).

A closer analysis of social-norms theory and research provides a potential explanation for the lack of effects and suggests the possibility of boomerang effects. Descriptive norms provide a standard from which people do not want to deviate. Because people measure the appropriateness of their behavior by how far away they are from the norm, being deviant is being above or below the norm. For example, although the majority of college students do overestimate the prevalence of alcohol consumption on campus (see Berkowitz, 2004, for a review), a substantial proportion of them—as many as one fifth by some estimates (e.g., Perkins et al., 2005) and nearly one half by others (e.g., Wechsler \& Kuo, 2000)— actually underestimate its prevalence. Because a social-norms marketing campaign provides specific descriptive normative information that can serve as a point of comparison for an individual's own behavior, the descriptive norm acts as a magnet for behavior for individuals both above and below the average. Consequently, a college campaign targeting alcohol consumption might motivate students who previously consumed less alcohol than the norm to consume more. Thus, although providing descriptive normative information may decrease an undesirable behavior among individuals who perform that behavior at a rate above the norm, the same message may actually serve to increase the undesirable behavior among individuals who perform that behavior at a rate below the norm.

Social-norms campaigns are intended to reduce problem behaviors (or increase prosocial behavior) by conveying the message that deleterious behaviors are occurring less often than most people think. But for 
individuals who already abstain from the undesirable behavior, such normative information can pro- duce unintended and undesirable boomerang effects. Is there a way to eliminate them? According to the focus theory of normative conduct (Cialdini et al., 1991), there is a second type of social norm, in addition to the descriptive norm, that has a powerful influence on behavior - the injunctive norm. Whereas descriptive norms refer to perceptions of what is commonly done in a given situation, injunctive norms refer to perceptions of what is commonly approved or disapproved within the culture (Reno, Cialdini, \& Kallgren, 1993). Focus theory predicts that if only one of the two types of norms is prominent in an individual's consciousness, it will exert the stronger influence on behavior (Cialdini \& Goldstein, 2004). Thus, in situations in which descriptive normative information may normally produce an undesirable boomerang effect, it is possible that adding an injunctive message indicating that the desired behavior is approved may prevent that effect.

\section{THE CURRENT RESEARCH}

The purpose of the current research was to explore how normative information may differentially affect an important social behavior depending on whether the message recipients' behavior is above or below the norm. In a California community, we performed a field experiment examining the effects of normative information on household energy consumption. All households received feedback about how much energy they had consumed in previous weeks and descriptive normative information about the average consumption of other households in their neighborhood. Households were divided into two categories at each observation period: those with energy consumption above average for the community and those with energy consumption below average for the community. Households were matched on a baseline measure of energy consumption, and then half of the households were randomly assigned to receive only the descriptive normative information. The other half received the descriptive normative information plus an injunctive message conveying that their energy consumption was either approved or disapproved; specifically, households that consumed less than the average received a message displaying a positively valenced emoticon (-) , whereas those that consumed more than the average received a message displaying a negatively valenced emoticon( $\odot$ ). The dependent measure was residents' subsequent actual household energy consumption.

We had three main predictions. First, we expected that descriptive normative information would decrease energy consumption in households consuming more energy than their neighborhood average. Such a result would be indicative of the constructive power of social norms, demonstrating that normative information can facilitate proenvironmental behavior. Second, we expected that descriptive normative information would increase energy consumption — that is, produce an undesirable boomerang effect-in households consuming less energy than their neighborhood average. Such a result would be indicative of the destructive power of social norms, demonstrating that a well-in- tended application of normative information can actually serve to decrease proenvironmental behavior. Third, we expected that providing both descriptive normative information and an in- junctive message that other people approve of lowconsumption behavior would prevent the undesirable boomerang effect in households consuming less energy than their neighborhood average; that is, we expected these households to continue to consume at low rates. Such a result would be indicative of the reconstructive power of injunctive messages to eliminate the untoward effects of a descriptivenorm.

\section{Method}

Participants and Design

Participants were 290 households in San Marcos, CA, with visible energy meters. They were selected from three census-block groups and notified about the study through a mailed letter. (Although they were 
offered the opportunity not to participate, none did so.) The study was a 2 (feedback: descriptive norm only vs. descriptivee plus injunctive information) X 2 (consumption: above- vs. below-average energy consumption) X 3 (time: base-line, short-term follow-up, longer-term follow-up) mixed-factorial design. Feedback and consumption were between-participants factors, and time was a within-participants factor.

\section{Procedure}

Prior to any experimental intervention, trained research assistants read the households' electricity meters twice within a 2 -week period. ${ }^{1}$ The difference between these two readings was used to establish an initial baseline measure of daily energy usage for each household. Households were matched on this baseline measure and randomly assigned to either the descriptive-norm-only condition or the descriptive-plusinjunctive-information condition. This initial baseline energy usage was used for the descriptive normative feedback and to determine the injunctive feedback for the first written message (i.e., whether the household consumed more or less than the average). Twoweeks later, researchers took a third meter reading and left written messages on residents' doors. These doorhangers reported energy consumption from the baseline period. One week after that, a second doorhanger was distributed; this message contained normative feedback that reported energy usage be- tween the second baseline reading and distribution of the first doorhanger. Researchers also took a fourth meter reading while distributing this second doorhanger. Wetook a finalmeter reading 3 weeks after the distribution of the second feedback message.

Short-term change in electricity usage was calculated by subtracting the meter reading taken the day the first message was distributed from the reading taken the day the second message was distributed. Longerterm change in electricity usage was calculated by subtracting the meter reading taken the day of the second message from the final meter reading.

\section{Intervention}

After the baseline period, households received a total of two messages left at their doors. For households in the descriptive- norm-only condition, each message contained(a) handwritten information about how much energy (in kilowatt-hours per day) they had used in the previous week (or weeks for the second doorhanger), (b) descriptive normative information about the actual energy consumption of the average household in their neighborhood during that same period (in kilowatt-hours per day), and (c) preprinted suggestions for how to conserve energy (e.g., use fans instead of air conditioning). Households in the descriptive-plus-injunctive-information condition received the same information as did those in the descriptive-norm-only group, with one key addition: If the household had consumed less than the average for the neighborhood, the researcher drew a happy face (-)); if the household had consumed more than the average, the researcher drew a sad face $(\Theta)$. The valence of the emoticon was used to communicate an injunctive message of approval or disapproval for the amount of energy being con- sumed. All messages were clearly identified with the university logo and a telephone number that could be used to contact our research team with questions or concerns.

\section{Results}

Of the 290 households, half were randomly assigned to receive the combined message (descriptive-norm feedback plus the injunc- tive emoticon), and the other half were randomly assigned to receive only the

\footnotetext{
${ }^{1}$ During the training of our research team, we assessed the reliability of our meter readings. On 157 occasions, two research assistants were assigned to read the same meter. These independent readings correlated at $r$ 5.999. In addition, during our training period, we were able to obtain electricity-usage data from the local utility company for 92 houses in this study. The correlation between this measure and our readings was .96 and .99 on 2 separate months.
} 
descriptive-norm feedback. Three households called to withdraw from the study following the initial normative- feedback distribution, resulting in a final sample of 287. At each measurement period, daily household energy consumption was positively skewed $(M=15.03$, $S D 57.10$, skew $=1.39$, range $=1.63-$ 35.88), resulting in more households below the mean than above. Although this introduced slightly unequal sample sizes for the above- and below-average groups, we used the mean as the dividing point for consumption because we believed it would provide a more meaningful number than other measures of central tendency when reported to residents.

\section{Short-Term Change in Electricity Usage}

The primary focus of our analyses was change in energy consumption, and our key interest was in the pair-wise comparison of baseline and follow-up usage in each of the four between- subjects cells (see Fig. 1a). For households that consumed more than the average during the baseline period, the descriptivenorm-only feedback produced a significant decrease in energy consumption relative to the baseline $(M=$ $20.25, S E=1.03$ vs. baseline $M=21.47, S E=0.89 ; n=64), t(63)=2.17, p_{\text {rep }}=.93, d=0.55$. Figure $1 \mathrm{a}$ shows this significant change as a reduction of $1.22 \mathrm{kWh}$ in daily energy consumption. Thus, the descriptive normative information led to the desired decrease in energy consumption for the households that were consuming more than the average for their neighborhood. This result illustrates the constructive potential of social norms.

In contrast, for households that were below the mean on baseline energy consumption, the descriptivenorm-only message produced an increase in energy consumption from baseline $(M=11.27, S E=0.46$ vs. baseline $M=10.38, S E=0.33 ; n=79), t(78)=2.28, p_{\text {rep }}=.94, d=50.52$. This change is shown in Figure $1 \mathrm{a}$ as an increase of $0.89 \mathrm{kWh}$ in daily energy consumption. Thus, the descriptive normative information led to an undesired increase in energy consumption for the households that were consuming less than the average for the neighborhood - a clear example of the destructive potential of social norms.

When the injunctive message was added to the descriptive normative feedback, households that were consuming less energy than average continued to consume at the desirable low rate $(M=10.58, S E=0.38 \mathrm{vs}$. baseline $M=10.34, S E=0.33 ; n=81), t(80)=1.04$, n.s. That is, the undesirable boomerang effect of increased usage among households low in energy consumption was eliminated when an injunctive message was added to the descriptive normative information. This result highlights the reconstructive potential of social norms. Finally, for households consuming above the average, the combined descriptive-plusinjunctive message served to decrease energy consumption $(M=18.91, S E=0.73$ vs. baseline $M=$ 20.63, $S E=0.64 ; n=63), t(62)=2.49, p_{\text {rep }}=.96, d=0.63$. 


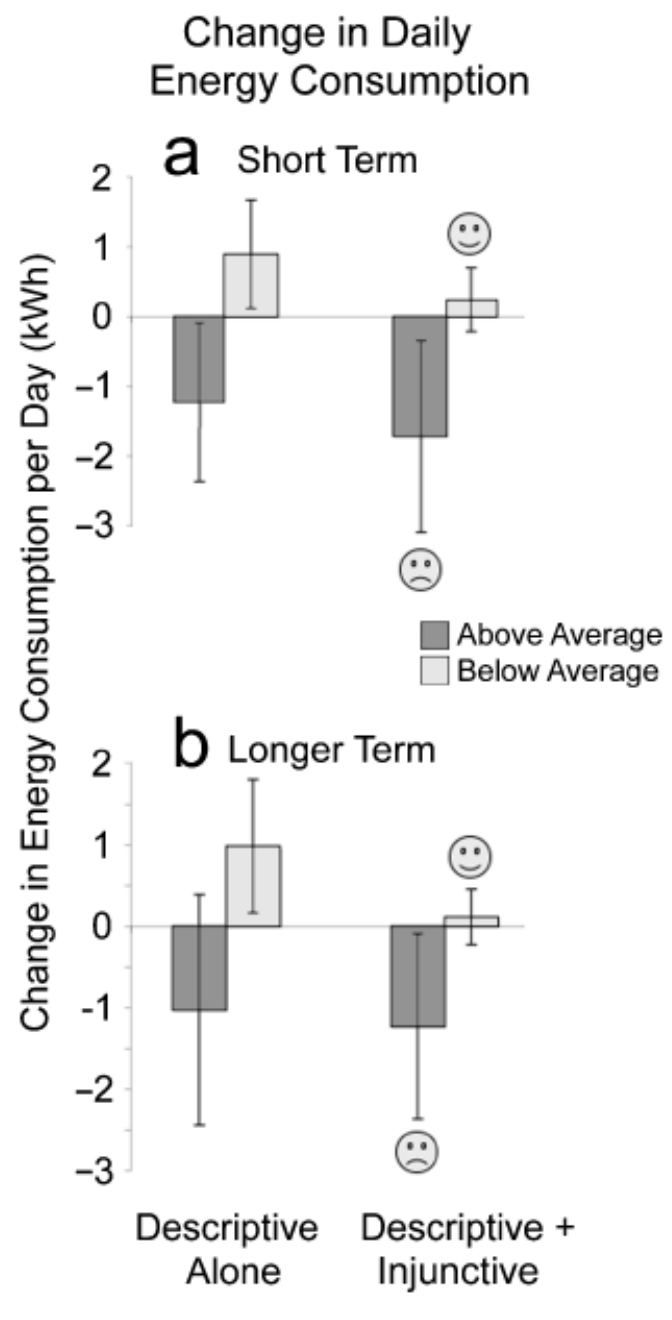

Feedback

Fig. 1. Difference between baseline daily energy consumption and daily energy consumption during the (a) shortterm and (b) longer-term follow- up periods. Results are shown for the four conditions created by crossing baseline energy consumption (above vs. below average) with feedback received (descriptive normative feedback only vs. descriptive feedback combined with an injunctive message). Error bars show the 95\% confidence interval of the pair-wise difference between usage during the follow-up period and during the baseline.

\section{Longer-Term Changes in Energy Consumption}

Of the 287 households in the study, 41 were inconsistently above or below the average across the 2 weeks of normative feedback and were therefore excluded from the analyses of longer-term change. There were no significant differences in inconsistency rate across the four experimental conditions.

Our analyses of longer-term change followed those for short- term change, focusing primarily on planned pair-wise comparisons of baseline and follow-up energy usage. As shown in Figure lb, the outcomes were nearly identical to those for the shorter-term measure. For those households that were high in energy consumption at baseline, the descriptive-norm-only message continued to produce the (constructive) decrease in energy consumption, although the difference was not conventionally significant (baseline $M=22.32, S E=1.05$ vs. longer- term $M=21.29$, $S E=0.92 ; n=52), t(51)=1.45$, n.s. For those households initially low in energy consumption, the descriptive- norm-only condition produced a significant increase in electricity usage (longer-term $M=11.13$, $S E=0.44$ vs. baseline $M=10.15, S E=$ $0.34 ; n=68), t(67)=2.42, p_{\text {rep }}=.95, d=0.59$. That is, the descriptive normative message continued 
to produce the (destructive) boomerang effect. However, the combined injunctive-plus-descriptive message produced no change from baseline for low-consuming households (longer- term $M=10.14, S E$ $=0.37$ vs. baseline $M=10.04, S E=0.35 ; n=70), t(69)=0.64$, n.s., again illustrating the reconstructive power of normative information when an injunctive element is added to the descriptive normative feedback. Finally, for households that initially consumed more energy than the neighborhood average, the combined descriptive-plus-injunctive feedback continued to produce a significant decrease in energy consumption relative to the baseline (baseline $M=20.62$, $S E=0.64$ vs. longer-term $M=19.39$, $S E$ $=0.62 ; n=56), t(55)=2.13, p_{\text {rep }}=.93, d=0.58$. Overall, the results for both the short-term measure and the longer-term measure were consistent with predictions.

\section{DISCUSSION}

The findings of this experiment are highly consistent with predictions derived from the focus theory of normative conduct (Cialdini et al., 1991). Providing residents with descriptive normative information had a dramatically different effect depending on whether they were initially above or below the average level of energy consumption in their neighborhood. Providing high-energy-consuming households with descriptive normativeinformation regarding the average home energy usage in their neighborhood constructively decreased energy consumption. In contrast, for households that were initially low in their base rates of energy consumption, the same descriptive message produced a destructive boomerang effect, leading to increased levels of energy consumption. However, adding an injunctive component to the message proved reconstructive by buffering this unwelcome boomerang effect. That is, for people who were initially low in energy consumption, the same descriptive normative information combined with an injunctive message of approval led to continued consumption at the desirable low rate, rather than a significant move toward the mean. Moreover, despite concerns that normative interventions have an effect for only a short time, the longer-term results indicate that the effects of the normative messages continued to be strong even 4 weeks after the initial intervention.

These findings provide a potential explanation for the mixed effects of normative messages in field contexts. Although social- norm campaigns are typically aimed at individuals whose behavior is less desirable than the norm, the widespread nature of these campaigns nearly ensures that those whose behavior is more desirable than the norm will also receive the message. Our results suggest that for those individuals who tend to engage in destructive behaviors, a descriptive normative message can be a guide to engaging in more constructive behavior; in contrast, for those individuals who already engage in the constructive behavior, a descriptive normative message can be a spur to engaging in more destructive behavior. For example, telling students that a majority of their peers drink " four or fewer drinks when they party" sends the message that abstaining from drinking is deviant. Our results demonstrate the potential for such messages to boomerang, but the results also show that an injunctive element of approval is reconstructive in its ability to ameliorate these unwanted effects.

Although the results from our field experiment are quite clear, there are several aspects that warrant additional comment. First, we should point out that the descriptive norm produced the boomerang effect among individuals who were already engaging in the desired behavior. Thus, the overall impact of a normative education campaign will depend on the distribution of the behavior in the population; a campaign could produce an increase, decrease, or no change in the behavior (the latter being most likely). For example, if the distribution of the target behavior is strongly skewed in the positive direction, such that more people are below the norm than above it, then a normative message might increase the behavior in aggregate. Second, prior research has suggested that presenting aligned descriptive and injunctive norms can result in larger behavioral changes than presenting either type of norm in isolation (Cialdini, 2003). Our results show this overall pattern, although the differences were not statistically significant. For example, in the short term, the reduction in energy usage for high-consuming households was 1.72 
$\mathrm{kWh}$ /day in the descriptive-plus-injunctive condition, compared with $1.22 \mathrm{kWh}$ /day in the descriptive-only condition. Finally, it is useful to consider potential boundary conditions that might limit the range of behaviors to which normative social influence would apply. The target behavior in this study (energy conservation) has a direct personal benefit (saving money), is private, is reoccurring (rather than a onetime action), and has widespread social approval. Although we believe that the current findings will apply to a range of other behaviors (e.g., alcohol consumption, seat-belt use, littering, consumer choices, illegal downloading of music), future research should explore the appropriate boundary conditions.

Acknowledgments-Funding for this study was provided by a grant from the Hewlett Foundation (20017396) and by National Science Foundation Graduate Research Fellowships to the fourth and fifth authors. Our appreciation goes to Veronica Briseño, Dulcinea Contreras, Matt Dorlaque, Reginald Hartfield, Edgar Medina, Laura Murphy, Leezel Nazareno, Rene Quiroz, Ronald Tilos, Monica Tinajero, and Christina Wade. Portions of this article were presented at the annual meeting of the American Psychological Society, Los Angeles, California, May 2005.

\section{REFERENCES}

Aarts, H., \& Dijksterhuis, A. (2003). The silence of the library: Environment, situational norm, and social behavior. Journal of Personality and Social Psychology, 84, 18-28.

Agostinelli, G., Brown, J., \& Miller, W.(1995). Effects of normative feedback on consumption among heavy drinking college students. Journal of Drug Education, 25, 31-40.

Baer, J.S., Stacy, A., \& Larimer, M. (1991). Biases in the perception of drinking norms among college students. Journal of Studies on Alcohol, 52, 580-586.

Berkowitz, A.D. (2004). An overview of the social norms approach. In

L. Lederman \& L. Stewart (Eds.), Changing the culture of college drinking (pp. 193-214). Cresskill, NJ: Hampton Press.

Borsari, B., \& Carey, K. (2003). Descriptive and injunctive norms in college drinking: A meta-analytic integration. Journal of Studies on Alcohol, 64, 331-341.

Cialdini, R.B. (2003). Crafting normative messages to protect the environment. Current Directions in Psychological Science, 12, 105-109.

Cialdini, R.B., \& Goldstein, N.J. (2004). Social influence: Compliance and conformity. Annual Review of Psychology, 55, 591-622.

Cialdini, R.B., Kallgren, C.A., \& Reno, R.R. (1991). A focus theory of normative conduct. Advances in Experimental Social Psychology, 24, 201-234.

Clapp, J.D., Lange, J.E., Russell, C., Shillington, A., \& Voas, R. (2003). A failed norms social marketing campaign. Journal of Studies on Alcohol, 64, 409-414.

Clapp, J.D., \& McDonnell, A. (2000). The relationship of perceptions of alcohol promotion and peer drinking norms to alcohol problems reported by college students. Journal of College Student Development, 41, 19-26.

Darley, J.M., \& Latané, B. (1970). Norms and normative behavior: Field studies of social interdependence. In J. Macaulay \&

L. Berkowitz (Eds.), Altruism and helping behavior (pp. 83-102). New York: Academic Press.

Donaldson, S.I., Graham, J.W., \& Hansen, W.B. (1994). Testing the generalizability of intervening mechanism theories: Under- standing the effects of adolescent drug use prevention interventions. Journal of Behavioral Medicine, 17, 195-216.

Donaldson, S.I., Graham, J.W., Piccinin, A.M., \& Hansen, W.B.(1995). Resistance-skills training and the onset of alcohol use: Evidence for beneficial and potentially harmful effects in public schools and in private Catholic schools. Health Psychology, 14, 291-300.

Goldstein, N.J., Cialdini, R.B., \& Griskevicius, V.(2006). A room with a viewpoint: Using normative 
appeals to motivate environmental conservation in a hotel setting. Manuscript submitted for publication.

Granfield, R. (2005). Alcohol use in college: Limitations on the trans- formation of social norms. Addiction Research and Theory, 13, 281-292.

Haines, M., \& Spear, S. (1996). Changing the perception of the norm: A strategy to decrease binge drinking among college students. Journal of American College Health, 45, 134-140.

Kerr, N.L. (1995). Norms in social dilemmas. In D. Schroeder (Ed.), Social dilemmas: Perspectives on individuals and groups (pp. 31-48). Westport, CT: Praeger.

Larimer, M.E., \& Neighbors, C. (2003). Normative misperceptions and the impact of descriptive and injunctive norms on college student gambling. Psychology of Addictive Behaviors, 17, 235-243.

Neighbors, C., Larimer, M., \& Lewis, M. (2004). Targeting misperceptions of descriptive drinking norms: Efficacy of a computer- delivered personalized normative feedback intervention. Journal of Consulting and Clinical Psychology, 73, 434-447.

Peeler, C.M., Far, J., Miller, J., \& Brigham, T.A. (2000). An analysis of the effects of a program to reduce heavy drinking among college students. Journal of Alcohol and Drug Education, 45, 39-54.

Perkins, H.W., \& Berkowitz, A.D. (1986). Perceiving the community norms of alcohol use among students: Some research implications for campus alcohol education programming. International Jour- nal of the Addictions, 21, 961-976.

Perkins, H.W., Haines, M.P., \& Rice, R. (2005). Misperceiving the college drinking norm and related problems: A nationwide study of exposure to prevention information, perceived norms and student alcohol misuse. Journal of Studies on Alcohol, 66, 470-478.

Prentice, D.A., \& Miller, D.T.(1993). Pluralistic ignorance and alcohol use on campus: Some consequences of misperceiving the social norm. Journal of Personality and Social Psychology, 64, 243-256.

Reno, R., Cialdini, R., \& Kallgren, C.A. (1993). The transsituational influence of social norms. Journal of Personality and Social Psychology, 64, 104-112.

Russell, C., Clapp, J.D., \& DeJong, W.(2005). “Done 4”’: Analysis of a failed social norms marketing campaign. Health Communication, 17, 57-65.

Schultz, P.W.(1999). Changing behavior with normative feedback in- terventions: A field experiment on curbside recycling. Basic and Applied Social Psychology, 21, 25-36.

Schultz, P.W., Tabanico, J., \& Rendón, T. (in press). Normative beliefs as agents of influence: Basic process and real-world applications. In R. Prislin \& W. Crano (Eds.), Attitudes and persuasion. New York: Psychology Press.

Terry, D.J., \& Hogg, M.A. (2001). Attitudes, behavior, and social context: The role of norms and group membership in social in- fluence processes. In J.P. Forgas \& K.D. Williams (Eds.), Social influence:

Direct and indirect processes (pp. 253-270). Philadel- phia: Psychology Press.

Wechsler, H., \& Kuo, M. (2000). College students define binge drinking and estimate its prevalence:

Results of a national survey. Journal of American College Health, 49, 57-60.

Wechsler, H., Nelson, T., Lee, J.E., Seiberg, M., Lewis, C., \& Keeling,

R. (2003). Perception and reality: A national evaluation of social norms marketing interventions to reduce college students' heavy alcohol use. Quarterly Journal of Studies on Alcohol, 64, 484-494. Werch,

C.E., Pappas, D.M., Carlson, J.M., DiClemente, C.C., Chally, P.M., \& Sinder, J.S. (2000). Results of a social norm intervention to prevent binge drinking among first-year residential college students. Journal of American College Health, 49, 85-92. 